\title{
Neonatal nicotine exposure causes insulin and leptin resistance and inhibits hypothalamic leptin signaling in adult rat offspring
}

\author{
Elaine de Oliveira ${ }^{1}$, Egberto G Moura ${ }^{1}$, Ana Paula Santos-Silva ${ }^{1}$, Cíntia R Pinheiro' ${ }^{1}$, Natalia S Lima ${ }^{1}$, \\ José Firmino Nogueira-Neto ${ }^{2}$, Andre L Nunes-Freitas ${ }^{1}$, Yael Abreu-Villaça ${ }^{1}$, Magna C F Passos ${ }^{3}$ \\ and Patrícia C Lisboa ${ }^{1}$ \\ ${ }^{1}$ Department of Physiological Sciences, Roberto Alcantara Gomes Biology Institute, ${ }^{2}$ Laboratory of Lipids, School of Medicine and ${ }^{3}$ Department of Applied \\ Nutrition, Nutrition Institute, State University of Rio de Janeiro, Avenida 28 de setembro, 87, Rio de Janeiro, RJ 20551-030, Brazil \\ (Correspondence should be addressed to P C Lisboa; Email: pclisboa@uerj.br)
}

\begin{abstract}
Maternal nicotine (NIC) exposure during lactation leads to overweight, hyperleptinemia, and hypothyroidism in adult rat offspring. In this model, we analyzed adipocyte morphology, glucose homeostasis (serum insulin and adiponectin; liver and muscle glycogen), serum lipid, and the leptin signaling pathway. After birth, osmotic minipumps were implanted in lactating rats, which were divided into the groups NIC (6 mg/kg per day s.c. for 14 days) and control (C, saline). NIC and $\mathrm{C}$ offspring were killed at the age of 180 days. Adult NIC rats showed higher total body fat $(+10 \%, P<0 \cdot 05)$, visceral fat mass $(+12 \%, P<0 \cdot 05)$, and cross-sectional area of adipocytes (epididymal: $+12 \%$ and inguinal: $+43 \%$, $P<0 \cdot 05)$. Serum lipid profile showed no alteration except for apolipoprotein AI, which was lower. We detected a lower adiponectin:fat mass ratio $(-24 \%, P<0 \cdot 05)$ and higher

insulinemia $(+56 \%, P<0 \cdot 05)$, insulin resistance index $(+43 \%, \quad P<0 \cdot 05)$, leptinemia $(+113 \%, P<0 \cdot 05)$, and leptin:adiponectin ratio $(+98 \%, P<0.05)$ in the adult NIC group. These rats presented lower hypothalamic contents of the proteins of the leptin signaling pathway (leptin receptor (OB-R): $-61 \%$, janus tyrosine kinase $2:-41 \%$, and $\mathrm{p}$-signal transducer and activator of transcription $3:-56 \%, P<0 \cdot 05)$, but higher suppressor of cytokine signaling $3(+81 \%$, $P<0 \cdot 05)$. Therefore, NIC exposure only during lactation programs rats for adipocyte hypertrophy in adult life, as well as for leptin and insulin resistance. Through the effects of NIC, perinatal maternal cigarette smoking may be responsible for the future development of some components of the metabolic syndrome in the offspring.

Journal of Endocrinology (2010) 206, 55-63
\end{abstract}

\section{Introduction}

Epidemiological and experimental data have shown that nutritional disorders and hormonal changes during critical periods of development and early life are associated with future changes in the structure and physiology of body tissues and systems of the progeny. This association has been named programming, which is defined as the basic biological phenomenon that putatively underlies the relationships among nutritional experiences in early life and diseases in adulthood (Barker 2003, Moura \& Passos 2005, De Moura et al. 2008). Also, the risk of developing chronic diseases in adulthood is influenced by environmental and dietary chemicals that can mimic or interfere with hormone action, known as endocrine disruptors. In fact, some of them may act as chemical 'obesogens' and promote obesity (Grun \& Blumberg 2006, Tabb \& Blumberg 2006).

Epidemiological studies show that maternal smoking during pregnancy might be a risk factor for childhood obesity and hypertension (Vik et al. 1996, Blake et al. 2000). Although the mechanisms to explain the development of

obesity under these circumstances are still unclear, some experimental data suggest that nicotine (NIC), the main addictive compound of tobacco smoke, in gestational and lactation periods, is responsible for increased adiposity in the offspring (Von Kries et al. 2002, Chen \& Kelly 2005, Gao et al. 2005, Goldani et al. 2007). In addition, we have recently shown that lactation is a crucial period for the programming of later obesity by NIC, with thyroid dysfunction being a possible contributing factor, since maternal NIC exposure only during lactation leads to overweight, higher central adiposity, hyperleptinemia, and secondary hypothyroidism in adult rat offspring (Oliveira et al. 2009).

Adipose tissue has a crucial role in metabolic disorders associated with obesity (Rasouli \& Kern 2008). Beyond secreting free fatty acids, the adipocytes release several proteins and hormones, such as leptin and adiponectin, with autocrine, paracrine, and endocrine functions (Matsuzawa 2006). Adiponectin production is inversely proportional to whole-body adipose mass, and experimental studies suggest that adiponectin increases insulin sensitivity in peripheral tissues (Matsuzawa 2006). Leptin, mainly produced by adipose tissue, reduces food 
intake and increases energetic expenditure (Friedman \& Halaas 1998), by signaling through the leptin receptor (OB-R or LEPR listed in the MGI Database). Six alternatively spliced isoforms of OB-R (, , b, c, d, e, and f) with different lengths of C-termini have been identified in mice. The long form (OB-Rb) is capable of active intracellular signaling (Lee et al. 1996). Leptin binding to OB-Rb initiates tyrosine phosphorylation by janus tyrosine kinase 2 (JAK2). Phosphorylated JAK2 recruits and phosphorylates signal transducer and activator of transcription 3 (STAT3). The activated STAT3 dimerizes and translocates to the nucleus, stimulating gene transcription. The JAK2/STAT3 pathway stimulates suppressor of cytokine signaling 3 (SOCS3) transcription, a leptin-inducible inhibitor of leptin signaling (Vaisse et al. 1996). In obesity, leptin resistance has been associated with changes in the JAK2/STAT3 pathway in the hypothalamus, with a decrease in $O B-R, J A K 2$, and STAT3 expression and an increase in SOCS3 content (Myers et al. 2008).

Because there is a high rate of smoking relapse among women who stopped smoking during pregnancy (McBride \& Pirie 1990), and because we have previously demonstrated that early NIC exposure during lactation is capable of affecting the future development of the offspring (Oliveira et al. 2009), possibly acting as an endocrine disruptor and an obesogen factor, the present study was designed to investigate the effects of perinatal NIC on intermediary metabolism. We evaluated adipocyte morphology, serum lipid, and protein levels, parameters related to glucose homeostasis (tissue glycogen, serum glucose, insulin, adiponectin, and corticosterone), and the expression of proteins of the leptin signaling pathway in the hypothalamus in the adult rat.

\section{Materials and Methods}

The use of the animals according to our experimental design was approved by the Animal Care and Use Committee of the Biology Institute of the State University of Rio de Janeiro (CEA/189/2007 and CEA/015/2009) that based its analysis on the principles adopted and promulgated by Brazilian Law (Law no. 11.794/2008). Experiments were conducted to minimize the number of animals and the suffering caused by the procedures following the ethical doctrine of the three 'Rs' - reduction, refinement, and replacement (Drummond 2009, Marques et al. 2009). Wistar rats were kept in a temperaturecontrolled room $\left(25 \pm 1{ }^{\circ} \mathrm{C}\right)$ with artificial dark-light cycles (lights on $0700 \mathrm{~h}$, lights off $1900 \mathrm{~h}$ ). Three-month-old, virgin female rats were caged with male rats at the ratio of $3: 1$. After mating, each female was placed in an individual cage with free access to water and food until delivery.

\section{Experimental model of neonatal NIC exposure}

Two days after birth, 12 lactating rats were randomly assigned to one of the following groups.
NIC $(\boldsymbol{n}=\mathbf{6})$ Dams were lightly anesthetized with thiopental, a $3 \times 6 \mathrm{~cm}$ area on the back was shaved, and an incision was made to permit s.c. insertion of osmotic minipumps (Alzet, 2ML2, Los Angeles, CA, USA). To avoid the adverse effects of NIC peaks, we chose to perform the NIC exposure by using s.c. osmotic mini pump infusion. Pumps were filled with NIC-free base diluted in $0.9 \% \mathrm{NaCl}$, to deliver an initial dose rate of $6 \mathrm{mg} / \mathrm{kg}$ of NIC per day (during 14 days of lactation), as previously described (Oliveira et al. 2009). At this rate, this paradigm produces plasma NIC levels similar to those observed in typical smokers, $\sim 25 \mathrm{ng} / \mathrm{ml}$ (Lichtensteiger et al. 1988). The incision was closed, and dams were permitted to recover in their home cages.

Control $(\boldsymbol{n}=\mathbf{6})$ Dams were implanted with osmotic minipumps containing only saline solution, used for the same period as the minipumps with NIC.

In general, pregnant rats produced 10-12 pups, and to avoid the influence of the litter size in the programming effect, we only used dams whose litter size was ten pups. At birth, to maximize the lactation performance, litters were adjusted to six male pups per NIC or control (C) dam. After weaning (21 days of lactation) until 180 days, body weight (BW) of the offspring was monitored every 4 days, as well as relative food intake (g/100 g BW) and body length were recorded every 15 days. Lee's index of obesity was determined in adult animals according to the following calculation: $\sqrt[3]{\text { body weight }}$ $(\mathrm{g}) /$ nasoanal length $(\mathrm{cm})$. We used two offspring from each mother, which were killed at the age of 180 days after $12 \mathrm{~h}$ of fasting. The killing occurred by quick decapitation, with no prior anesthesia (because anesthesia affects hormone and lipid metabolism), to collect blood, hypothalamus, liver, muscle, and visceral and subcutaneous fat.

\section{Detection of NIC metabolite in blood and milk}

Serum and milk cotinine levels were determined using a cotinine assay kit from Orasure Technologies (Bethlehem, PA, USA) in accordance with the manufacturer's recommendations. On the 15 th day of lactation, dams were separated from their litters, and $2 \mathrm{~h}$ later, milk was collected as previously described (Bonomo et al. 2005) and stored at $-20{ }^{\circ} \mathrm{C}$ until assayed. After that, dams (NIC, $n=6$; C, $n=6$ ) and pups (NIC, $n=6$; C, $n=6$ ) were killed, and blood was collected. Blood was centrifuged $(2000 \mathrm{~g}, 20 \mathrm{~min})$, and supernatant was stored $\left(-20^{\circ} \mathrm{C}\right)$ until the time of assay.

\section{Computed tomography}

To study the adipose distribution, we performed computed tomography (GE - helicoidal HiSpeed - CUCC/HUPE /UERJ). Three-millimeter axial sections were obtained to evaluate the adipose tissue content (one section per rat, $n=12$ rats per group). Adult NIC and C offspring were lightly anesthetized with thiopental, and put in dorsal 
decubitus for the computed tomography. Analyses of adipocyte cross-sectional area $\left(\mathrm{cm}^{2}\right)$ were determined using the program DicomWorks v1.3.5 Software (http://dicom. online.fr/).

\section{Morphometric analysis of adipocytes}

Visceral (epididymal) and subcutaneous (inguinal) white adipose tissues were fixed in a paraformaldehyde solution and embedded in paraffin, and $5-\mu \mathrm{m}$ sections were stained with hematoxylin/eosin. Morphometric measurements were performed on 12 serial sections taken every $100 \mu \mathrm{m}$ for each animal. Four adipocytes were measured in each section ( 48 cells analyzed per rat, $n=6$ rats per group), and the cross-sectional area of each adipocyte was determined using Image J 1.34s software (Wayne Rasband National Institute of Health, Bethesda, MA, USA).

\section{Tissue glycogen content}

Soleus muscles were weighed and homogenized in Turrax with $1 \mathrm{ml}$ buffer $(50 \mathrm{mM}$ Tris- $\mathrm{HCl} ; 5 \mathrm{mM} \mathrm{NaF}$; $5 \mathrm{mM}$ EGTA; and $1 \mathrm{mM}$ dithiothreitol; $\mathrm{pH} 7 \cdot 2$ ). After centrifugation $\left(2000 \mathrm{~g}\right.$ at $4{ }^{\circ} \mathrm{C}$ for $\left.20 \mathrm{~min}\right), 600 \mu \mathrm{l}$ of supernatant was removed and frozen. On the next day, $100 \mu \mathrm{l}$ of supernatant was incubated with $2 \mathrm{U}$ of amyloglucosidase from Aspergillus niger (Sigma A7420), suspended in 0.2 M Na acetate, $\mathrm{pH} 4 \cdot 8$, in a final volume of $200 \mu \mathrm{l}$, for $4 \mathrm{~h}$ at $40{ }^{\circ} \mathrm{C}$. A standard curve with increasing concentrations of glycogen was constructed using the same experimental conditions. The glucose produced by glycogen hydrolysis was measured using a commercial kit (Glucox, Doles, Goiás, Brazil). To ensure that glucose originated only from glycogen, blanks without enzyme were carried through the same procedure and subtracted from the experimental samples (Casimiro-Lopes et al. 2008).

Livers were weighed and homogenized in Turrax with $4 \mathrm{ml}$ of trichloroacetic acid (TCA; 10\%). After centrifugation $\left(1000 \mathrm{~g}\right.$ at $4{ }^{\circ} \mathrm{C}$ for $\left.10 \mathrm{~min}\right), 2 \mathrm{ml}$ of supernatant was added to $5 \mathrm{ml}$ of absolute ethanol and frozen. After $24 \mathrm{~h}$, the mixture was centrifuged $\left(1000 \mathrm{~g}\right.$ at $4{ }^{\circ} \mathrm{C}$ for $\left.10 \mathrm{~min}\right)$, and the supernatant was discarded. Glycogen was hydrolyzed by boiling the pellet for $30 \mathrm{~min}$ with $1 \mathrm{M} \mathrm{HCl}$. After addition of $1 \mathrm{ml}$ of $1 \mathrm{M} \mathrm{NaOH}$ to neutralize the mixture, glucose was measured in $200 \mu \mathrm{l}$ of supernatant as described above (Casimiro-Lopes et al. 2008).

\section{Biochemical analysis}

Serum levels of total cholesterol (TC), triglycerides, highdensity lipoprotein cholesterol (HDL-C), low-density lipoprotein cholesterol (LDL-C), and very low-density lipoprotein cholesterol (VLDL-C) were analyzed using Biosystem commercial test kits with an automated A15 spectrophotometer (Biosystems S.A., Barcelona, Spain). LDL-C and VLDL-C were calculated according to the equation of Friedwald:

VLDL-C $=$ triglycerides $/ 5$

LDL-C $=($ TC - HDL-C - triglycerides $) / 5$

Apo AI and Apo B concentrations were measured by immunoturbidimetric assay using an automated A15 BioSystems Analyzer.

A biuret reaction was performed for total plasma protein measurement, and the absorbance of products was determined on spectrophotometer (automated A15 BioSystems Analyzer). Plasma albumin was determined by the bromocresol green method, and globulin fraction was measured by the difference between total protein and albumin. Values are expressed as $\mathrm{mg} / \mathrm{dl}$.

\section{Hormonal determination by RIA}

Blood samples were centrifuged $\left(1500 \mathrm{~g} / 20 \mathrm{~min}\right.$ per $\left.4{ }^{\circ} \mathrm{C}\right)$ to obtain serum, which was frozen $\left(-20^{\circ} \mathrm{C}\right)$ until assaying. All measurements were performed in one assay; all samples were analyzed in duplicate. Insulin concentration was determined using an RIA kit (ICN Pharmaceuticals Inc., Orangeburg, NY, USA) with an assay sensitivity of $0.1 \mathrm{ng} / \mathrm{ml}$ and an intraassay variation of $4 \cdot 1 \%$. Adiponectin was measured with a specific RIA kit (Linco Research, St Charles, MO, USA) with an assay sensitivity of $0.5 \mathrm{ng} / \mathrm{ml}$ and an intra-assay variation of $7 \cdot 1 \%$. Leptin was measured with a specific RIA kit (Linco Research, Inc.), which measures both rat and mouse leptin with a range of detection from 0.5 to $50 \mathrm{ng} / \mathrm{ml}$; the intra-assay variation was $2.9 \%$. Corticosterone was measured using a specific RIA kit (ICN Biomedicals Inc., Aurora, $\mathrm{OH}, \mathrm{USA}$ ) with an assay sensitivity of $50 \mathrm{ng} / \mathrm{ml}$ and an intra-assay variation coefficient of $7 \%$.

\section{Insulin sensitivity}

Fasting blood glucose was determined from the tail vein of fasting rats using a glucometer (ACCU-CHEK Advantage; Roche Diagnostics). To determine the insulin sensitivity of adult animals, we used the insulin resistance index (IRI): fasting insulin $(\mu \mathrm{IU} / \mathrm{ml}) \times$ fasting glucose $(\mathrm{mmol} / \mathrm{l})$. As hypertropic adipocytes secrete more leptin and less adiponectin, the serum leptin:adiponectin ratio (LAR) was used to evaluate insulin resistance and vascular risk (Finucane et al. 2009). Also, plasma adiponectin levels were normalized to whole-body fat mass (Park et al. 2005).

\section{Western blotting analysis}

The hypothalamus was isolated using the coordinates established by the Atlas of Neuroanatomy: with Systems Organization and Case Correlations (Warner 2001). To obtain cell extracts, hypothalamic tissues were homogenized in ice-cold lysis buffer $\left(50 \mathrm{mM}\right.$ HEPES, $1 \mathrm{mM} \mathrm{MgCl}_{2}$, $10 \mathrm{mM}$ EDTA, Triton X-100 1\%, pH 6.4) containing the 
following protease inhibitors: $10 \mu \mathrm{g} / \mu \mathrm{l}$ aprotinin, $10 \mu \mathrm{g} / \mu \mathrm{l}$ leupeptin, $2 \mu \mathrm{g} / \mu \mathrm{l}$ pepstatin, and $1 \mathrm{mM}$ phenylmethylsulfonyl fluoride (Sigma-Aldrich). Ob-R, JAK2, STAT3, and SOCS3 content were analyzed by western blotting as described below, using actin as internal control.

Total protein content in the hypothalamus homogenate was determined by the BCA protein kit assay (Rockford, IL, USA), and cell lysates were denatured in sample buffer (50 mM Tris- $\mathrm{HCl}$, pH 6.8, 1\% SDS, 5\% 2-mercaptoethanol, $10 \%$ glycerol, and $0 \cdot 001 \%$ bromophenol blue) and heated at $95^{\circ} \mathrm{C}$ for $5 \mathrm{~min}$. Samples (30 $\mu \mathrm{g}$ total protein) were run in $10 \%$ SDS-PAGE and transferred to polyvinylidene filters (PVDF Hybond-P, Amersham Pharmacia Biotech). Rainbow markers (Amersham Biosciences) were run in parallel to estimate molecular weights. Membranes were blocked with $5 \%$ nonfat milk in Tween-TBS $(20 \mathrm{mM}$ Tris- $\mathrm{HCl}, \mathrm{pH} 7 \cdot 5$, $500 \mathrm{mM} \mathrm{NaCl}$, and $0 \cdot 1 \%$ Tween-20). Primary antibodies (Santa Cruz Biotechnology, Inc., Santa Cruz, CA, USA) used were anti-OB-R (1:500), anti-JAK2 (1:500), anti-STAT3 (1:500), anti-p-STAT3 (1:500), anti-SOCS3 (1:500), and anti-actin (1:1000). PVDF filters were washed three times with Tween-TBS $(0 \cdot 1 \%)$, followed by incubating $1 \mathrm{~h}$ with the appropriate secondary antibody conjugated to biotin (Santa Cruz Biotechnology, Inc). Then, filters were incubated with streptavidin-conjugated HRP (Caltag Laboratories, Burlingame, CA, USA). All western blots were allowed to react with HRP substrate (ECL-plus; Amersham Pharmacia Biotech), and then exposed to X-ray film for $10 \mathrm{~s}$ to $30 \mathrm{~min}$. In most cases, the membranes were stripped (Restore Western Blot Stripping buffer; Pierce, Rockford, IL, USA) at $37^{\circ} \mathrm{C}$ for $15 \mathrm{~min}$, washed with Tween-TBS $(0 \cdot 1 \%)$ three times, and reprobed with specific primary antibody, following all steps above. Images were scanned, and the bands were quantified by densitometry, using Image J 1.34s software (Wayne Rasband National Institute of Health).

\section{Statistical analysis}

Results are reported as mean \pm s.E.M. The GraphPad Prism 5 (GraphPad Software, Inc., La Jolla, CA, USA) was used for statistical analyses and graphics. Data were analyzed by unpaired Student's $t$-test, and differences were considered significant at $P<0 \cdot 05$.

\section{Results}

Milk and serum cotinine levels

NIC treatment affected cotinine milk and plasma levels. In the NIC dams, milk and serum cotinine concentrations were similar (milk: $225 \cdot 8 \pm 7 \cdot 1 \mathrm{ng} / \mathrm{ml}$; serum: $239 \cdot 7$ $\pm 25 \cdot 2 \mathrm{ng} / \mathrm{ml}$ ). NIC pups at the age of 15 days had serum cotinine levels of $20 \cdot 4 \pm 1.5 \mathrm{ng} / \mathrm{ml}$. Control dams and pups had cotinine levels below the detection limit of the technique $(<8 \mathrm{ng} / \mathrm{ml})$.
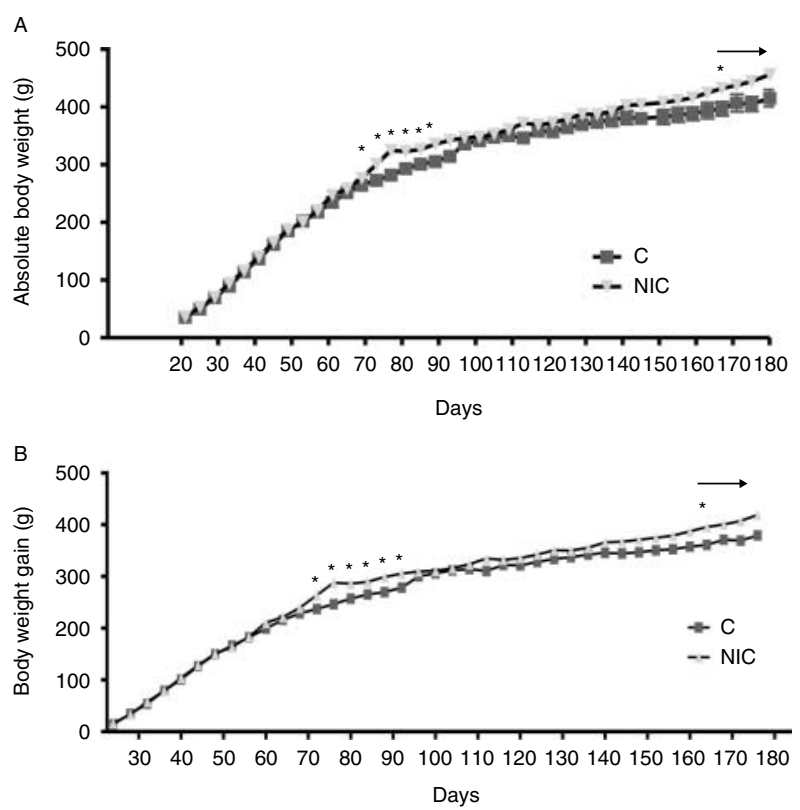

Figure 1 Absolute body weight (A) and body weight gain (B) after weaning of offspring whose mothers were nicotine (NIC) or saline (C) exposed during lactation ( $n=12$ animals per group), $P<0 \cdot 05$.

\section{Nutritional evaluation}

We found higher BW gain for NIC offspring between 75 and 100 days of life (around 10\%, $P<0 \cdot 05$ ) as well as after the age of 165 days, reaching $10 \%(P<0 \cdot 05)$ at the age of 180 days (Fig. 1). At adulthood, NIC offspring showed higher Lee's index scores $(+7 \%, P<0 \cdot 05)$ compared with controls; however, they exhibited no differences concerning body length and food intake (Table 1).

Central and total adiposity were higher in adult NIC rats $(+10$ and $+12 \%$ respectively, $P<0 \cdot 05$; Fig. $2 \mathrm{C}$ and $\mathrm{D})$. Subcutaneous fat content did not show any significant change (Fig. 2E). To determine whether the increase in fat mass in NIC offspring was associated with an increase in the size of adipocytes (hypertrophy), we performed morphometric analysis on histological sections of visceral and subcutaneous adipose tissue (Fig. 3A and B). Quantitative analysis of

Table 1 Nutritional parameters and glycogen content of adult offspring from control and nicotine-exposed dams

\begin{tabular}{lccc} 
& \multicolumn{1}{c}{ C } & NIC \\
\cline { 2 - 2 } Body length $(\mathrm{cm})$ & $25 \cdot 4 \pm 0 \cdot 2$ & & $24 \cdot 8 \pm 0 \cdot 2$ \\
Body weight $(\mathrm{g})$ & $414 \cdot 9 \pm 14 \cdot 8$ & & $455 \cdot 9 \pm 8 \cdot 9^{*}$ \\
Lee's index $(\mathrm{g} 1 / 3 / \mathrm{cm})$ & $0 \cdot 30 \pm 0 \cdot 002$ & & $0 \cdot 32 \pm 0 \cdot 004^{*}$ \\
Food intake $(\mathrm{g})$ & $31 \cdot 44 \pm 0 \cdot 6$ & & $33 \cdot 83 \pm 0 \cdot 2$ \\
Liver glycogen $(\mathrm{mM} / \mathrm{g})$ & $1 \cdot 32 \pm 0 \cdot 03$ & & $1 \cdot 22 \pm 0 \cdot 02^{*}$ \\
Muscle glycogen $(\mu \mathrm{M} / \mathrm{ml} \mathrm{g})$ & $22 \cdot 16 \pm 4 \cdot 2$ & & $48 \cdot 81 \pm 5 \cdot 6^{*}$
\end{tabular}

C, control offspring; NIC, nicotine offspring. Values represent mean \pm s.E.M. of 12 rats per group $\left({ }^{*} P<0 \cdot 05\right)$. 
A

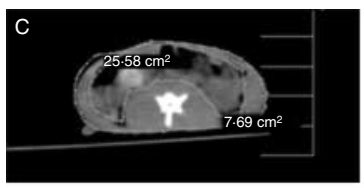

B
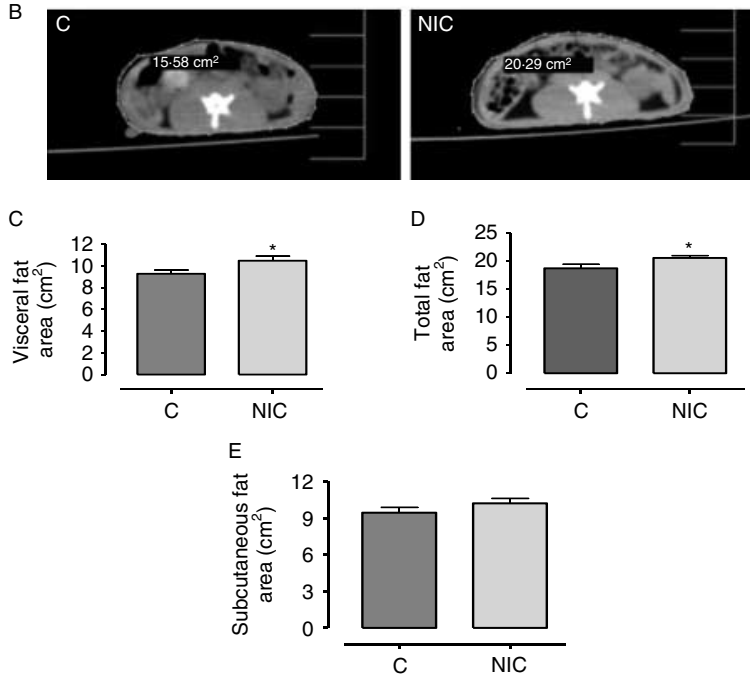

Figure 2 Computed tomography of abdominal sections in rats, in dorsal decubitus, to measurement of visceral adipose tissue. Figures $A$ and $B$ represent tomography images of central $(A)$ and total $(B)$ adiposity from individual NIC and C offspring. Mean of visceral (C), total (D), and subcutaneous (E) adipose tissue areas was expressed in $\mathrm{cm}^{2}$ ( $n=12$ animals per group), $P<0 \cdot 05$.

these sections showed that both epididymal and inguinal adipocytes were larger in NIC rats compared with controls (Fig. 3C: $+12 \%$ and Fig. 3D: $+43 \%$ respectively; $P<0 \cdot 05$ ). NIC offspring exhibited higher serum leptin concentrations $(+113 \%, P<0 \cdot 05$; Fig. 4G).

As depicted in Table 2, no significant difference was detected in serum TC, HDL-C, LDL-C, VLDL-C, or triglycerides, nor for serum globulins, albumin, or total protein levels. However, Apolipoprotein (Apo) AI protein was lower in the NIC animals at the age of 180 days $(-66 \%$, $P<0 \cdot 05)$.

\section{Glucose homeostasis}

NIC rats presented lower liver glycogen $(-8 \%, P<0 \cdot 05)$ and higher muscle glycogen $(+120 \%, P<0 \cdot 05)$ in adulthood (Table 1).

Adult rats whose mothers were exposed to NIC during lactation had no significant difference in fasting blood glucose (Fig. 4A), corticosterone (Fig. 4D), or adiponectin (Fig. 4E), in spite of a lower adiponectin/VFM ratio $(-24 \%, P<0.05$; Fig. $4 \mathrm{~F})$, higher blood insulin $(+56 \%, P<0 \cdot 05$; Fig. 4B), higher IRI $(+43 \%, P<0 \cdot 05$; Fig. 4C), and a higher LAR ( $+98 \%, P<0 \cdot 05$; Fig. $4 \mathrm{H})$ when compared with control rats.

\section{Hypothalamic leptin signaling}

The NIC group showed lower OB-R (-61\%, Fig. 5A), JAK2 (-41\%, Fig. 5B), p-STAT3 (-56\%, Fig. 5D), and higher SOCS3 expression ( $+81 \%$, Fig. 5E) in the hypothalamus at the age of 180 days $(P<0 \cdot 05$ for all). Additionally, a lower ratio of p-STAT3 to total STAT3 was observed in the NIC group compared with the $\mathrm{C}$ group $(-40 \%, P<0 \cdot 05$; data not shown).

\section{Discussion}

Some studies have found an increased risk of obesity in children whose mothers smoked during pregnancy (Vik et al. 1996, Von Kries et al. 2002). Our group has been studying several imprinting factors during lactation, such as nutritional and hormonal status, which are capable of programming body composition and endocrine function in adult life (Toste et al. 2006, De Moura et al. 2007, Passos et al. 2007, Lisboa et al. 2008). Also, we have recently shown that NIC exposure during lactation programs the offspring to exhibit overweight, higher serum leptin levels, and hypothyroidism in adulthood (Oliveira et al. 2009). In fact, our findings regarding obesity corroborate those of other researchers (Newman et al. 1999, Chen \& Kelly 2005, Gao et al. 2005), who have studied the effects of prenatal and postnatal
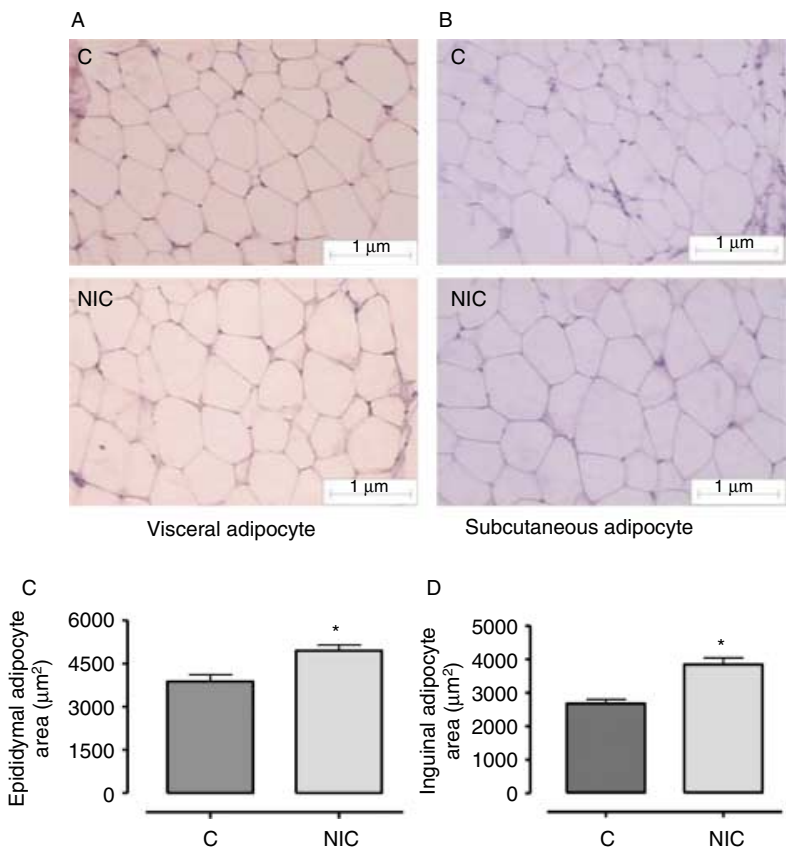

Figure 3 Histological sections of epididymal (A) and subcutaneous (B) white adipose tissue at 180-day-old offspring whose mothers were nicotine or saline exposed during lactation. Mean area of visceral (C) and subcutaneous (D) adipocyte was expressed in $\mu \mathrm{m}^{2}$ ( $n=6$ animals per group), $P<0 \cdot 05$. Objective $20 \times$. Full colour version of this figure available via http://dx.doi.org/10.1677/ JOE-10-0104. 

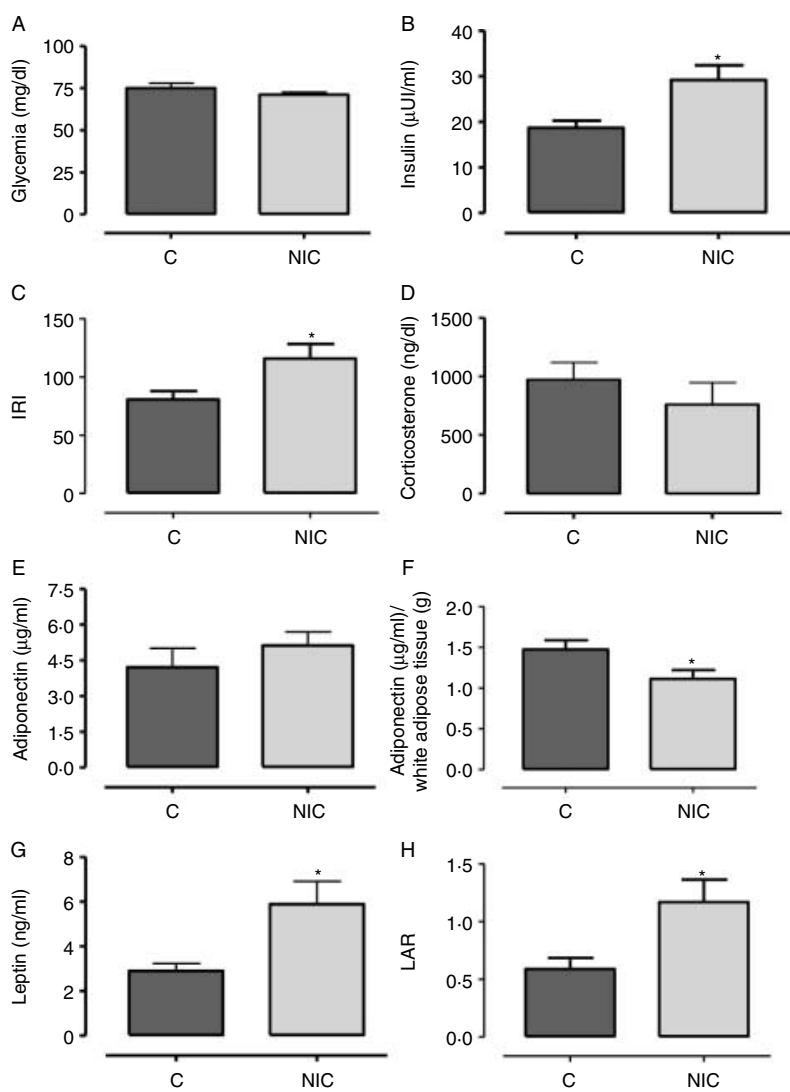

Figure 4 Serum glucose (A), insulin (B), IRI (C), corticosterone (D), adiponectin $(E)$, and ratio adiponectin/visceral fat mass $(F)$, leptin $(\mathrm{G})$, and LAR $(\mathrm{H})$ at 180-day-old offspring whose mothers were nicotine or saline exposed during lactation. Values represent mean \pm S.E.M. of 12 rats per group; $* P<0 \cdot 05$

NIC exposure and have suggested that NIC can be an endocrine disruptor and obesogen.

It is important to consider that there are developmental differences between rodents and humans. Some structures that are immature in rat at birth, mature only in postnatal period (in the first week of life), whilst in humans occur since the second trimester of gestation, for example, lactation in rats is a critical period to NIC exposure, corresponding roughly, at least concerning the neural development in the second trimester of gestation in humans (Vinay et al. 2005).

An infusion rate of $6 \mathrm{mg} / \mathrm{kg}$ per day NIC in rats produces serum NIC levels similar to those observed in typical smokers, $\sim 25 \mathrm{ng} / \mathrm{ml}$ (Lichtensteiger et al. 1988). To simulate this situation during lactation, rat dams were implanted with osmotic minipumps releasing $6 \mathrm{mg} / \mathrm{kg}$ per day continuously (Oliveira et al. 2009). We chose the period of lactation because this period exhibits a high rate of smoking relapse among women who stopped smoking during pregnancy (McBride \& Pirie 1990). Cotinine is the main NIC metabolite, and the serum NIC:cotinine ratio is $1: 5$ to $1: 10$ (Trauth et al. 2000). In the present study, we found high levels of serum cotinine in NIC mothers $(239 \mathrm{ng} / \mathrm{ml})$ as well as in their milk $(225.8 \mathrm{ng} / \mathrm{ml})$, which translated to a serum cotinine concentration of $20.4 \mathrm{ng} / \mathrm{ml}$ in NIC pups. We then exposed NIC dams to NIC at levels comparable to those of heavy smoking mothers. We detected low cotinine concentrations in the NIC pups. Because NIC is transferred through the milk (Luck \& Nau 1987), perhaps this observation can be explained by the separation of the pups from their mothers for $2 \mathrm{~h}$, which could underestimate the real impact of maternal NIC exposure.

Lee's index (an obesity indicator) and central and total adiposity, as evaluated by computed tomography, were higher in adult NIC offspring, which corroborates our previous finding of overweight (Oliveira et al. 2009) and confirms the reproducibility of our experimental model. Morphological analyses of the adipose tissue revealed hypertrophy of the epididymal (visceral) and inguinal (subcutaneous) adipocytes in adult NIC rats. This indicates that the obesity in offspring induced by maternal NIC exposure may be due to adipocyte hypertrophy. Although the number of fat cells has not been measured in this study, we cannot rule out that hyperplasia also occurs in this model. Overexpression of PparG, a key transcription factor in adipocyte differentiation and adipose physiology, has been detected in weaned rats that were prenatally exposed to NIC (Somm et al. 2008). The incubation of rat adipocytes with NIC caused a dosedependent increase of tumor necrosis factor, adiponectin, and free fatty acid secretion into the medium (Liu et al. 2004). Therefore, it is possible that NIC acts directly on adipocytes, affecting gene expression and/or hormonal secretion, which could be the initial link between early NIC exposure and later obesity.

It has been reported that NIC treatment alters the lipid profile of adult female rats (Abd el Mohsen et al. 1997). In the present study, despite their overweight and higher adiposity, NIC offspring showed no change in triglycerides, TC, LDL-C, HDL-C, or VLDL-C levels, which is in agreement with our previous data (Oliveira et al. 2009). Apo AI is present in HDL-C, which is considered an antiatherogenic factor

Table 2 Serum biochemical parameters of offspring from control and nicotine-exposed dams

\begin{tabular}{ccc}
\multicolumn{1}{c}{ C } & \multicolumn{1}{c}{ NIC } \\
$59 \cdot 1 \pm 1 \cdot 9$ & & $53 \cdot 3 \pm 3 \cdot 1$ \\
$12 \cdot 7 \pm 0 \cdot 8$ & & $13 \cdot 8 \pm 1 \cdot 1$ \\
$33 \cdot 6 \pm 1 \cdot 9$ & & $32 \cdot 5 \pm 3 \cdot 4$ \\
$12 \cdot 8 \pm 1 \cdot 1$ & & $14 \cdot 8 \pm 4 \cdot 8$ \\
$64 \cdot 1 \pm 5 \cdot 6$ & & $50 \cdot 6 \pm 2 \cdot 9$ \\
$29 \cdot 5 \pm 6 \cdot 96$ & & $10 \cdot 0 \pm 2 \cdot 55^{*}$ \\
$16 \cdot 1 \pm 2 \cdot 67$ & & $12 \cdot 8 \pm 2 \cdot 31$ \\
$7 \cdot 9 \pm 0 \cdot 18$ & & $7 \cdot 4 \pm 0 \cdot 28$ \\
$3 \cdot 1 \pm 0 \cdot 10$ & & $2 \cdot 8 \pm 0 \cdot 14$ \\
$4 \cdot 9 \pm 0 \cdot 10$ & & $4 \cdot 6 \pm 0 \cdot 19$
\end{tabular}

HDL cholesterol, high-density lipoprotein cholesterol; LDL cholesterol, lowdensity lipoprotein cholesterol; VLDL cholesterol, very low-density lipoprotein cholesterol; Apo, apolipoprotein; C, control offspring; NIC, nicotine offspring. Values represent mean \pm s.E.M. of 12 rats per group $\left({ }^{*} P<0 \cdot 05\right)$. 
A

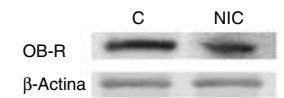

B

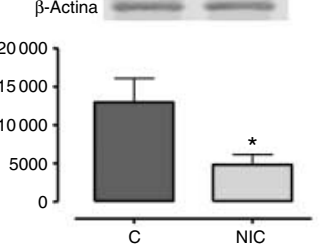

C
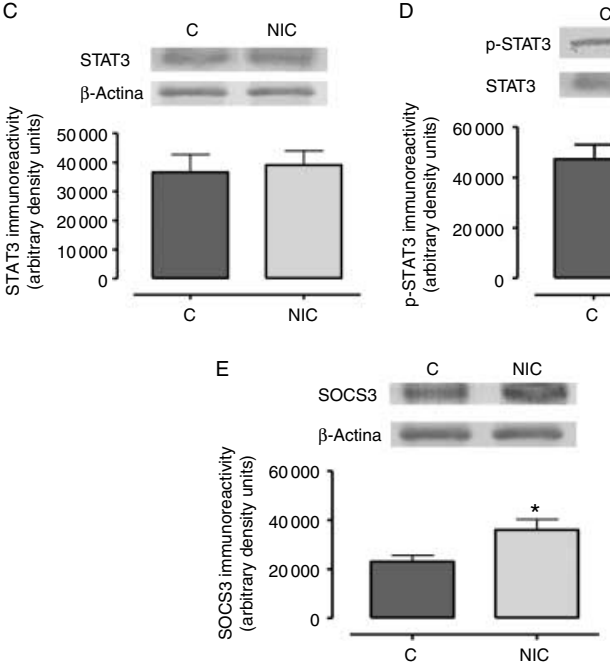

Figure 5 Effect of maternal nicotine exposure on protein expression of leptin signaling pathway in hypothalamus of adult rats ( 180 days old). Homogenates of hypothalamus from $\mathrm{C}$ and $\mathrm{NIC}$ groups were obtained, and OB-R (A), JAK2 (B), STAT3 (C), p-STAT3 (D), and SOCS3 (E) detections were performed by western blotting. Bands on the top figure represent the protein expression in hypothalamus homogenate from individual $\mathrm{C}$ and NIC offspring. OB-R, JAK2, STAT3, p-STAT3, and SOCS3 content were quantified by scanning densitometry of the bands ( $\mathrm{AU}$, arbitrary units). Actin content was used as control loading. Results are expressed as mean \pm s.E.M. ( $n=6$ rats per group), $* P<0 \cdot 05$. A representative experiment is shown from three independent experiments.

(Onat et al. 2009). In the present study, we also detected lower serum Apo AI concentrations in NIC rats. This finding may indicate a chronic subclinical inflammation. We also evaluated total serum protein, albumin, and globulin concentrations, which are important to the overall nutritional assessment. Despite their overweight condition, NIC rats presented no alteration of these parameters at the age of 180 days.

Some studies have shown that fetal and postnatal NIC exposure causes impaired glucose tolerance in neonatal offspring (Somm et al. 2008). According to Bruin et al. (2007), NIC exposure from conception until lactation results in permanent $\beta$-cell depletion and subsequent impaired glucose tolerance. Therefore, the development of diabetes requires that NIC exposure occurs in both gestation and lactation periods. In fact, in our experimental model, no changes in fasting blood glucose or adiponectin were observed in adult NIC rats. Serum corticosterone, which is also involved in the control of glucose homeostasis, was unchanged. However, we detected hyperinsulinemia and a higher IRI in adult NIC offspring. Moreover, their LAR was higher, and when we calculated the ratio of adiponectin to white adipose tissue mass, we observed lower adiponectin production per gram of adipose tissue. Taken together, these findings suggest that our programmed animals developed insulin resistance. Insulin has well-known stimulatory effects on glycogen synthesis, and this helps to explain the higher glycogen content in skeletal muscle in adulthood. The lower liver glycogen content may indicate the early steps of selective insulin resistance induced by maternal NIC exposure during lactation. In addition, adult NIC rats are hyperleptinemic (Oliveira et al. 2009), and since leptin also stimulates glycogen synthesis (Aiston \& Agius 1999), it is possible that the programmed rats developed leptin resistance in liver but not in muscle.

As already mentioned, neonatal NIC exposure programs higher adiposity and hyperleptinemia but does not affect food intake (Oliveira et al. 2009). Thus, we evaluated the leptin signaling pathway in the hypothalamus. We observed lower OB-R, JAK2, and p-STAT3 expression as well as higher SOCS3 expression in the hypothalami of adult rats submitted to neonatal NIC exposure. These data suggest resistance to the anorexigenic effect of leptin, which could explain why the higher serum leptin levels in adult NIC group did not change the food intake.

We cannot discern whether the present data is caused by a direct or an indirect NIC effect. Recently, we observed that NIC-treated dams presented hyperprolactinemia and, consequently, higher milk production with higher lactose concentration and energy content. However, in the weaning period (after NIC withdrawal), these dams showed only hyperleptinemia (Oliveira et al. 2010). So, at least three hypotheses are possible to explain the NIC action in our model of programming by neonatal NIC exposure. First, NIC transfer through milk (Luck \& Nau 1987, Narayanan et al. 2002) may alter some factor(s) in offspring. Secondly, maternal changes caused by NIC treatment can be transferred to the pups through the milk. And thirdly, the programming by neonatal NIC exposure may be due to biochemical, hormonal, or behavior changes in either the mothers or pups. In general terms, epigenetic mechanisms, such as DNA methylation or histone acetylation/deacetylation, induced by neonatal environmental factors (nutrition, hormones, or endocrine disruptors) may lead to an increased risk of metabolic disorders in the adult progeny (De Moura et al. 2008). Thus, this explanation could help to explain the mechanism involved in the permanent changes to $\mathrm{BW}$ regulation induced by early NIC exposure. Whether NIC can make children exposed to cigarette smoke during the postnatal period more susceptible to obesity and other metabolic and endocrine disorders in adulthood warrants epidemiological and prospective studies.

In summary, we have shown that maternal NIC exposure during lactation programs offspring for adipocyte 
hypertrophy and central leptin resistance in adult life, which may explain their adulthood overweight. We conclude that through the effects of NIC, maternal smoking in the critical period of lactation can be responsible for the future development of some components of the metabolic syndrome in progeny.

\section{Declaration of interest}

The authors declare that there is no conflict of interest that could be perceived as prejudicing the impartiality of the research reported.

\section{Funding}

This research was supported by the 'National Council for Scientific and Technological Development' (Conselho Nacional de Desenvolvimento Científico e Tecnológico-CNPq), the 'Carlos Chagas Filho Research Foundation of the State of Rio de Janeiro' (Fundação Carlos Chagas Filho de Amparo à Pesquisa do Estado do Rio de Janeiro-FAPERJ), and Coordination for the Enhancement of Higher Education Personnel (Coordenação de Aperfeiçoamento de Pessoal de Nível Superior - CAPES).

\section{Acknowledgements}

All the authors are grateful to Antonio C M de Sá, Vania Pinto, and Ana Maria B Coutinho from Laboratory of Lipids (LabLip, UERJ) for lipid profile determination. We also thank Mr Carlos Roberto, Miss Monica Moura, and Mr Luciano Santos for technical assistance.

\section{References}

Abd el Mohsen MM, Fahim AT, Motawi TM \& Ismail NA 1997 Nicotine and stress: effect on sex hormones and lipid profile in female rats. Pharmacological Research 35 181-187.

Aiston S \& Agius L 1999 Leptin enhances glycogen storage in hepatocytes by inhibition of phosphorylase and exerts an additive effect with insulin. Diabetes 48 15-20.

Barker DJ 2003 The developmental origins of adult disease. European Journal of Public Health 18 733-736.

Blake KV, Gurrin LC, Evans SF, Beilin LJ, Landau LI, Stanley FJ \& Newnham JP 2000 Maternal cigarette smoking during pregnancy, low birth weight and subsequent blood pressure in early childhood. Early Human Development 57 137-147.

Bonomo IT, Lisboa PC, Passos MC, Pazos-Moura CC, Reis AM \& Moura EG 2005 Prolactin inhibition in lactating rats changes leptin transfer through the milk. Hormone and Metabolic Research 37 220-225.

Bruin JE, Kellenberger LD, Gerstein HC, Morrison KM \& Holloway AC 2007 Fetal and neonatal nicotine exposure and postnatal glucose homeostasis: identifying critical windows of exposure. Journal of Endocrinology 194 171-178.

Casimiro-Lopes G, Alves SB, Salerno VP, Passos MCF, Lisboa PC \& Moura EG 2008 Maximum acute exercise tolerance in hyperthyroid and hypothyroid rats subjected to forced swimming. Hormone and Metabolic Research 40 276-280.

Chen WJ \& Kelly RB 2005 Effect of prenatal or perinatal nicotine exposure on neonatal thyroid status and offspring growth in rats. Life Sciences $\mathbf{7 6}$ $1249-1258$

De Moura EG, Lisboa PC, Custodio CM, Nunes MT, de Picoli Souza K \& Passos MC 2007 Malnutrition during lactation changes growth hormone mRNA expression in offspring at weaning and in adulthood. Journal of Nutritional Biochemistry 18 134-139.
De Moura EG, Lisboa PC \& Passos MC 2008 Neonatal programming of neuroimmunomodulation - role of adipocytokines and neuropeptides. Neuroimmunomodulation 15 176-188.

Drummond GB 2009 Reporting ethical matters in the Journal of Physiology: standards and advice. Journal of Physiology 587 713-719.

Finucane FM, Luan J, Wareham NJ, Sharp SJ, O'Rahilly S, Balkau B, Flyvbjerg A, Walker M, Højlund K \& Nolan JJ 2009 Correlation of the leptin:adiponectin ratio with measures of insulin resistance in non-diabetic individuals. Diabetologia 52 2345-2349.

Friedman JM \& Halaas JL 1998 Leptin and the regulation of body weight in mammals. Nature 395 763-770.

Gao YJ, Holloway AC, Zeng ZH, Lim GE, Petrik JJ, Foster WG \& Lee RM 2005 Prenatal exposure to nicotine causes postnatal obesity and altered perivascular adipose tissue function. Obesity Research 13 687-692.

Goldani MZ, Haeffner LSB, Agranonik M, Barbieri MA, Bettiol H \& Silva AAM 2007 Do early life factors influence body mass index in adolescents? Brazilian Journal of Medical and Biological Research 40 1231-1236.

Grun F \& Blumberg B 2006 Environmental obesogens: organotins and endocrine disruption via nuclear receptor signaling. Endocrinology 147 S50-S55.

Lee GH, Proenca R, Montez JM, Carroll KM, Darvishzadeh JG \& Friedman JM 1996 Abnormal splicing of the leptin receptor in diabetic mice. Nature 379 632-625.

Lichtensteiger W, Ribary U, Schlumpf M, Odermatt B \& Widmer HR 1988 Prenatal adverse effects of nicotine on the developing brain. Progress in Brain Research 73 137-157.

Lisboa PC, Fagundes AT, Denolato AT, Oliveira E, Bonomo IT, Alves SB, Curty FH, Passos MC \& Moura EG 2008 Neonatal low-protein diet changes deiodinase activities and pituitary TSH response to TRH in adult rats. Experimental Biology and Medicine 233 57-63.

Liu RH, Mizuta M \& Matsukura S 2004 The expression and functional role of nicotinic acetylcholine receptors in rat adipocytes. Journal of Pharmacology and Experimental Therapeutics 310 52-58.

Luck W \& Nau H 1987 Nicotine and cotinine concentrations in the milk of smoking mothers: influence of cigarette consumption and diurnal variation. European Journal of Pediatrics 146 21-26.

Marques RG, Morales MM \& Petroianu A 2009 Brazilian law for scientific use of animals. Acta Cirúrgica Brasileira 24 69-74.

Matsuzawa Y 2006 Therapy insight: adipocytokines in metabolic syndrome and related cardiovascular disease. Nature Clinical Practice. Cardiovascular Medicine 3 35-42.

McBride CM \& Pirie PL 1990 Postpartum smoking relapse. Addictive Behaviors 15 165-168.

Moura EG \& Passos MC 2005 Neonatal programming of body weight regulation and energetic metabolism. Bioscience Reports 25 251-269.

Myers MG, Cowley MA \& Munzberg H 2008 Mechanisms of leptin action and leptin resistance. Annual Review of Physiology 70 537-556.

Narayanan U, Birru S, Vaglenova J \& Breese CR 2002 Nicotinic receptor expression following nicotine exposure via maternal milk. Neuroreport 13 961-963.

Newman MB, Shytle RD \& Sanberg PR 1999 Locomotor behavioral effects of prenatal and postnatal nicotine exposure in rat offspring. Behavioural Pharmacology 10 699-706.

Oliveira E, Moura E, Santos-Silva A, Fagundes AT, Rios AS, Abreu-Villaça Y, Nogueira Neto JF, Passos MC \& Lisboa PC 2009 Short and long-term effects of maternal nicotine exposure during lactation on body adiposity, lipid profile and thyroid function of rat offspring. Journal of Endocrinology 202 397-405.

Oliveira E, Pinheiro CR, Santos-Silva AP, Trevenzoli IH, Abreu-Villaça Y, Nogueira Neto JF, Reis AM, Passos MCF, Moura EG \& Lisboa PC 2010 Nicotine exposure affects mother's and pup's nutritional, biochemical, and hormonal profiles during lactation in rats. Journal of Endocrinology 205 $159-170$.

Onat A, Can G, Ayhan E, Kaya Z \& Hergenç G 2009 Impaired protection against diabetes and coronary heart disease by high-density lipoproteins in Turks. Metabolism 58 1393-1399. 
Park SY, Cho YR, Kim HJ, Higashimori T, Danton C, Lee MK, Dey A, Rothermel B, Kim YB, Kalinowski A et al. 2005 Unraveling the temporal pattern of diet-induced insulin resistance in individual organs and cardiac dysfunction in C57BL/6 mice. Diabetes 54 3530-3540.

Passos MC, Lins MC, Lisboa PC, Toste FP, Bonomo IT \& de Moura EG 2007 Maternal leptin treatment during lactation programs the thyroid function of adult rats. Life Sciences 80 1754-1758.

Rasouli N \& Kern PA 2008 Adipocytokines and the metabolic complications of obesity. Journal of Clinical Endocrinology and Metabolism 93 S64-S73.

Somm E, Schwitzgebel VM, Vauthay DM, Camm EJ, Chen CY, Giacobino JP, Sizonenko SV, Aubert ML \& Hüppi PS 2008 Prenatal nicotine exposure alters early pancreatic islet and adipose tissue development with consequences on the control of body weight and glucose metabolism later in life. Endocrinology 149 6289-6299.

Tabb MM \& Blumberg B 2006 New modes of action for endocrinedisrupting chemicals. Journal of Molecular Endocrinology 20 475-482.

Toste FP, de Moura EG, Lisboa PC, Fagundes AT, de Oliveira E \& Passos MC 2006 Neonatal leptin treatment programmes leptin hypothalamic resistance and intermediary metabolic parameters in adult rats. British Journal of Nutrition 95 830-837.

Trauth JA, Seidler FJ \& Slotkin TA 2000 An animal model of adolescent nicotine exposure: effects on gene expression and macromolecular constituents in rat brain regions. Brain Research 867 29-39.
Vaisse C, Halaas JL, Horvath CM, Darnell JE Jr, Stoffel M \& Friedman JM 1996 Leptin activation of Stat3 in the hypothalamus of wild-type and ob/ob mice but not db/db mice. Nature Genetics 14 95-97.

Vik T, Jacobsen G, Vatten L \& Bakketeig LS 1996 Pre- and post-natal growth in children of women who smoked in pregnancy. Early Human Development 19 245-255.

Vinay L, Ben-Mabrouk F, Brocard F, Clarac F, Jean-Xavier C, Pearlstein E \& Pflieger JF 2005 Perinatal development of the motor systems involved in postural control. Neural Plasticity 12 131-139.

Von Kries R, Toschke AM, Koletzko B \& Slikker W Jr 2002 Maternal smoking during pregnancy and childhood obesity. Americam Journal of Epidemiology 156 954-961.

Warner JJ 2001 Major divisions of the cerebral hemispheres demonstrated on references sections. In Atlas of Neuroanatomy: With Systems Organization and Case Correlations, edn 1, pp 65-71. Butterworth-Heinemann: Oxford.

Received in final form 29 April 2010

Accepted 6 May 2010

Made available online as an Accepted Preprint

7 May 2010 